\title{
The KNOW HOWse project at the Solar Decathlon Middle East 2018 Dubai: an academia-industry cooperation to train a new generation of professionals for the green-building challenge
}

\author{
Vittorino Belpoliti ${ }^{1 *}$, Marta Calzolari ${ }^{2}$, Osama Hassan ${ }^{3}$, Reem Nassif ${ }^{4}$ \\ ${ }^{1,2,3,4}$ University of Sharjah, United Arab Emirates
}

\begin{abstract}
Sustainability and energy efficiency are among the priorities of UAE Government to limit energy consumption and greenhouse gas emission. The UAE construction sector is rapidly implementing green-building standards in the market by introducing energy efficient materials and techniques. However, the subsidized cost of electricity causes unfeasible payback periods to the initial investment for such techniques and materials. Therefore, the energy market needs to be boosted by creating a culture of sustainability. Such strategy requires educating a new generation of professionals, provided with the awareness and skills to serve the local community and operate in the challenging construction market. The University of Sharjah and the University of Ferrara, in cooperation with local and international authorities and industry, present the KNOW HOWse project, an energy efficient prototype house designed, built, and operated by students, that participated to the Solar Decathlon Middle East 2018 in Dubai.
\end{abstract}

Index Terms - Green-building, Project-based learning, Solar Decathlon, Sustainability

\section{INTRODUCTION}

\section{A. Energy performance of the building sector in the UAE}

Sustainability and energy efficiency are among the priorities of Government of countries all around the world, including the UAE.

The oil era has evidently affected the UAE approach to environmental sustainability, overall in regards to Greenhouse Gas emissions. Nonetheless, the UAE Vision 2021, launched in 2010 by H.H. Sheikh Mohammed bin Rashid Al Maktoum, Vice-President and Prime Minister of

Manuscript received April 21, 2019. Consulting partners: Sharjah Investment and Development Authority - Shurooq; Sheikh Zayed Housing Programme.

Sponsors and supporters: Alba Tower Construction; DUBCO Construction; Xlam Dolomiti; Pandre Special Integration; OffGrid Group of Companies; Schueco Middle East; ALICO Aluminium and Light Industries; Gulf Glass Industries; OHM Star Electromechanic; Bee'ah Sharjah Environment Company; Alufoot; Master Events; Watergy International Group; Buzzi \& Buzzi; Aquamag - Magnesia Panel Building Material Trading; Al Weqaya Fire Fighting; Soltech; Rothoblaas; Crestron; Hydraloop international; The Mail Room Restaurant \& Cafe; Risala Furniture; Italian Industry \& Commerce Office in the UAE; Sharjah Architectural Student Association

Vittorino Belpoliti, Osama Hassan, and Reem Nassif are with the Architectural Engineering Department, University of Sharjah, Sharjah 27272, UAE (e-mail: vbelpoliti@ sharjah.ac.ae).

Marta Calzolari is with the Department of Architecture - University of Ferrara, Via della Ghiara 36, 44121 Ferrara, Italy (e-mail: marta.calzolari@unife.it). the UAE and Ruler of Dubai [1] aims at making the UAE among the most innovative nations in the world.

The Vision 2021 strives for achieving a sustainable environment through several actions, among which the energy

upgrade of the building sector, the largest energy consumer in the western UAE, accounting for nearly $70 \%$ of the total national electricity consumption [2].

\section{B. Residential energy consumption. An educational problem}

The UAE per capita Ecological Footprint is among the largest in the world (the largest in 2006 - Living Planet Report 2006 [3]). Within the country's whole energy consumption, the largest share is accountable to the residential sector, and most precisely to Nationals and wealthy expats whose accommodations have high-energy expenses. Such energyconsuming habits are the result of a lacking education regarding the energy emergency, fostered by the governmental policies that, subsidize the cost of electricity [4], [5], that have two major downsides:

- Reducing the users' energy bills to the extent of not feeling variations in energy consumption;

- Making energy-efficient construction features, such as implementation of photovoltaic devices or installation of high-performance glazing systems, financially unfeasible as their payback time becomes too long (sometimes longer than the expected life of product/device).

\section{RESEARCH-BASED DESIGN}

\section{A. Simulating the professional activity at the Solar Decathlon Middle East 2018 in Dubai}

Given the above scenario, the building energy sector needs to be boosted by generating awareness sustainability with publicly supported initiatives, such as the Solar Decathlon Middle East 2018 (SDME) [6], a university competition organized by DEWA [7] were students from around the world compete in the "Olympics of green architecture". Furthermore, it is fundamental to inform the younger members of society to be more aware of energy and resource consumptions. To this regard, a new class of professionals of the building sector needs to be educated in order to face this challenge, and more engaging ways of teaching need to be introduced in order to involve students first hand. 
The University of Sharjah - UAE and the Research Centre Architettura>Energia of the University of Ferrara - Italy contributed to this educational discourse partnering in the Team KNOW HOWse [8], a multi-disciplinary group of students and instructors participating to the SDME with an energy-efficient prototype building designed, operated and run/occupied by students.

\section{B. Performance-based design}

Performance-based design is a method to address architectural design, focusing on the functional performance of the building. It implies the identification of the building's requirements and their ideal solution, even without referring to specific methods or rules. This is in contrast to conventional prescribed building codes, but suits the UAE scenario, where local regulations still lack detailed guidelines. To this regard, performance-based design is a technical and objective model to adopt in architectural engineering education, since it proposes the development of own tools and methods to evaluate the requirements of a

building-type and meet them.

Furthermore, the SDME organization placed significant emphasis on building performance (mostly regarding energy), in the form of a strict program. In order to meet the targeted energy performance goals, specific design measures were selected and put into practice after performing simulation of each one. They were taught the commercial software Design Builder® [9], a dynamic-state energy simulation software that runs detailed energy performance analysis. The tool aided the students experimenting several options and self-teaching the best design result, including:

- Modeling various spatial layouts to limit the cooling loads;

- Optimizing window to wall ratio, accounting for glazing and frame type;

- Optimizing shading elements size and location;

- Testing several cladding systems and coatings;

- Analyzing the impact of thermal bridges on the building envelope performance;

- Planning for passive cooling and ventilation strategies.

\section{Workshops and brainstorming sessions}

Shaping a convincing concept around a set of design's requirements is often the hardest part for students. To this regard, the members of the team met together on scheduled days dedicated to brainstorming session and workshops. Basic brainstorming techniques helped students developing problem-solving skills to address and solve the design issues (Fig. 1). During these sessions instructors and students debated possibilities, simulating a typical office workday.

The direct discussion between students and with instructors helped developing a design concept that was the real result of the function-based analysis, free from formal stereotypes.

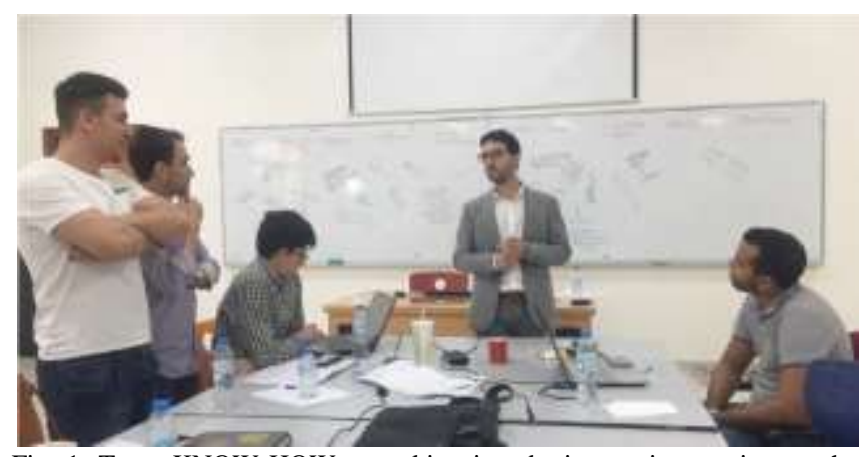

Fig. 1. Team KNOW HOWse working in a brainstorming session, at the University of Sharjah.

\section{Sponsor networking}

As a self-funded project, it was necessary to partner with companies for sponsorship agreements. The availability and types of sponsors established throughout the project have dictated, to some extent, the possibility of executing many features of the house. Guided by faculty members, students were heavily involved in the networking activity, conducted in various methods.

Searching companies online was mostly beneficial as a preliminary action, giving students an idea of available building products, both nationally and internationally, as often, the reality of the local market would impose limitations and changes to initial ideas of the project.

Major partners were sought by contacting governmental agencies that shared a mutual interest in the housing sector. Most remaining sponsors were reached by:

Attending events related to the building industry; • Developing network chains through connections;

- Visiting local companies for specific products.

Attending construction-related events was efficient in reaching potential sponsors in a short period of time (Fig. 2). In many cases, however, it was unfeasible to finalize agreements with these companies after further study.

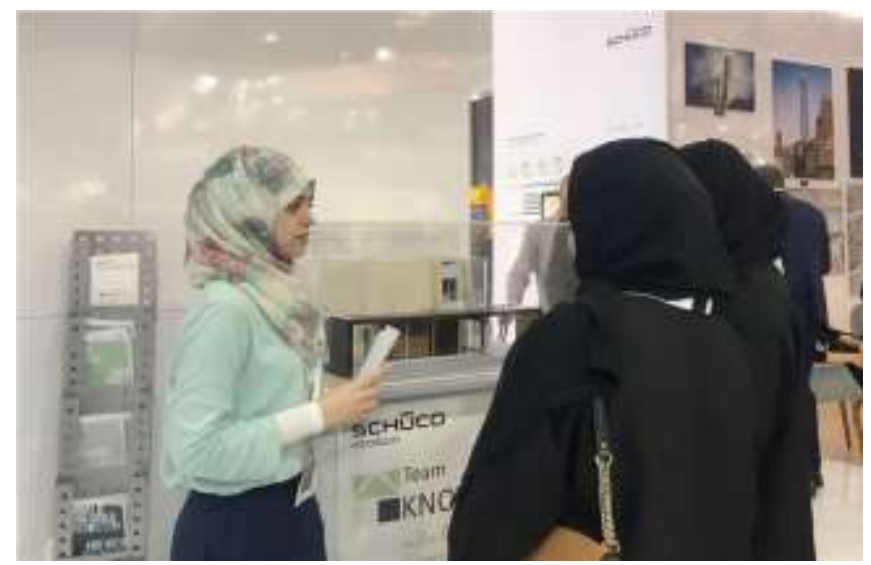

Fig. 2. Students' dissemination of the KNOW HOWse project at Windows, Doors, \& Facades 2017, hosted at a sponsor's stand. 
Nevertheless, the exhibitions offered an understanding of market-available technology, which determined design features to possibly embed in the house. They served as communication platforms for students to publicize the project, raising awareness on its educational aim (Fig. 3).
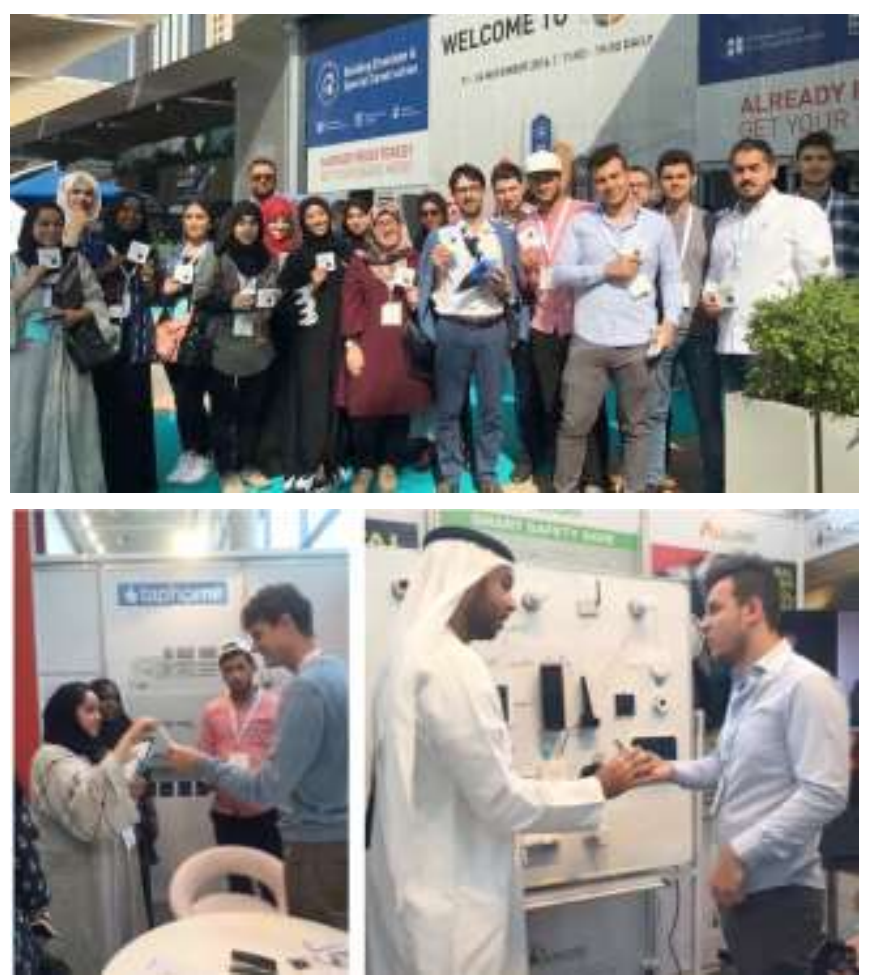

Fig. 3. Student members of Team KNOW HOWse networking at the BIG 5

2016 Dubai, one of the construction-related events attended to meet potential sponsors.

Although reaching companies through personal connections was more limited than the previous methods and took a longer time, it was sometimes more effective in finalizing agreements.

In addition to the obstacles mentioned above, students found challenging following up with contacts, scheduling meetings, and negotiating agreements. Moreover, reaching decision makers was often difficult because of bureaucracy and/or poor communication. Besides, students were not always capable of determining whether the interested company was qualified to perform the required tasks. This led to another major challenge, which was companies withdrawing from or changing major parts of preliminary agreements.

Instructors, who guided students in all networking activities, viewed the process as a pedagogical instrument to prepare the new generation of professionals to advance in the market. Simultaneously, this teaching method would provide the construction sector, which is shifting towards green buildings and sustainability, with more aware professionals.

Bottom line, the need to involve students in the construction sector provided incentives for both parties (university and industry) to collaborate and work together, resulting in an innovative and dynamic pedagogical model.
Students received extensive training that toned their soft skills (such as communication, team work, leadership, negotiation, etc.).

Eventually, the team established a vast network of sponsors that supported the project in different ways. The sponsorship provided by these companies belonged to either one of the following types:

- Direct financial sponsorship;

- Indirect financial sponsorship (where the sponsor would pay subcontractors to provide their services);

- Direct in-kind sponsorship (in the form of products and/or services).

\section{PROJECT-BASED LEARNING}

\section{A. Construction}

Students' involvement in construction work was maximized during the entire period of the project. Instructors would prepare the involved students for detailed construction and work techniques by delivering targeted workshops, courses and on-site work and training. Construction activity would happen in a dedicated site within the campus of the University of Sharjah - UAE, it would be supervised by instructors and aided by construction technicians and professional laborers belonging to the sponsoring companies.

From the first stages of the project, students and instructors elaborated detailed design and shop drawings, keeping in mind that the building was going to be built.

Such documents kept being updated for improvements throughout the whole project. In addition to the basic working drawing set, students learnt how to execute special assembly manuals and instructions, site operation plan, and health and safety plan for the particular logistic of the project.

Work on site was a continuous learning process for over a year of the total project. Instructors and students dealt with all construction requirements and issues, with special regard to the peculiar structural system chosen for the house, the Cross Laminated Timber (CLT), sponsored by an Italian company. The innovative introduction of wooden structures in the UAE offered a great opportunity of exposing students to a full learning experience, as most of the time, skilled instructors needed to teach the inexpert laborers too. The partner University of Ferrara - Italy brought expertise and direct construction force (instructors and skilled students) to ease this necessary know-how transfer.

Students became confident with constructing the house step by step (Fig. 4). In the process they also learnt first-hand construction methods, verified material properties, understood a structure's behavior in full scale, dealt with mechanical, electrical, and plumping systems.

During the construction phases, students had to coordinate most sponsoring partners, material suppliers, and sponsors. This activity further enriched the experience, as it was a 
completely new practice, only slightly introduced in the university curriculum (courses of Project Management and Professional Practice). Teamwork was crucial to efficiently and professionally coordinate the project.

The student's exposure to practical construction activity especially involved an approach to green-buildings and energy efficiency. Physical experience with the materials used and understating of their properties and utilization made students more aware to construction-related sustainability topics, like:

Materials storage and handling;

- Construction waste management;

- Carbon footprints and sustainable properties of building materials and products;

- Feasible construction process through organized tasks scheduling;

- Maximized use of recycled materials and smart re-use of waste-material.

This specific target, promoted by the SDME itself, prepared new generations of architecture and engineering students to move in a holistic and aware fashion within the sustainability sector, which will surely play a key role in their future professional activity.

The learning overall experience can be considered successful, even though some obstacles have been encountered due to the students' inexperience, mostly in certain construction tasks, and academic duties, which sometimes were not compatible with suppliers' and workers schedule.

\section{B. Testing phase/contest}

The final phase of the SDME competition required to disassemble the solar house, transport it, and re-assemble it at the Mhd bin Rashid Solar Park in Dubai. In a period of only 14 days the house was fully re-built by the team members, undergoing all the necessary inspections and strict health \& safety checks (Fig. 5).

Finally, with the house ready, the operation phase (10 days of contest) started. The sole students, coached by instructors, run the house and the domestic task to monitor its energy performance. Students had assigned roles and responsibilities working as an organized team with different working shifts, taking care of running specific house functions and tasks (Fig. 6).

During this testing/contest phase, students also delivered public tours to the visitors and competition jurors to showcase the house features and design. This assignment required the students to practice on communication, in order to be concise and targeted, adding value to the overall learning experience (Fig. 7).

During the entire 10-day contest phase, all monitoring data was provided live by the competition organizers, for the students to continuously observe them and make the necessary adjustments to the house operation in order to improve the scoring and optimal results. As already mentioned, all the above tasks where the sole responsibility of a team of student, while the instructors only supervised them remotely. Even the unexpected challenges that arose, such as failures of the house appliances, would be and solved by the students.

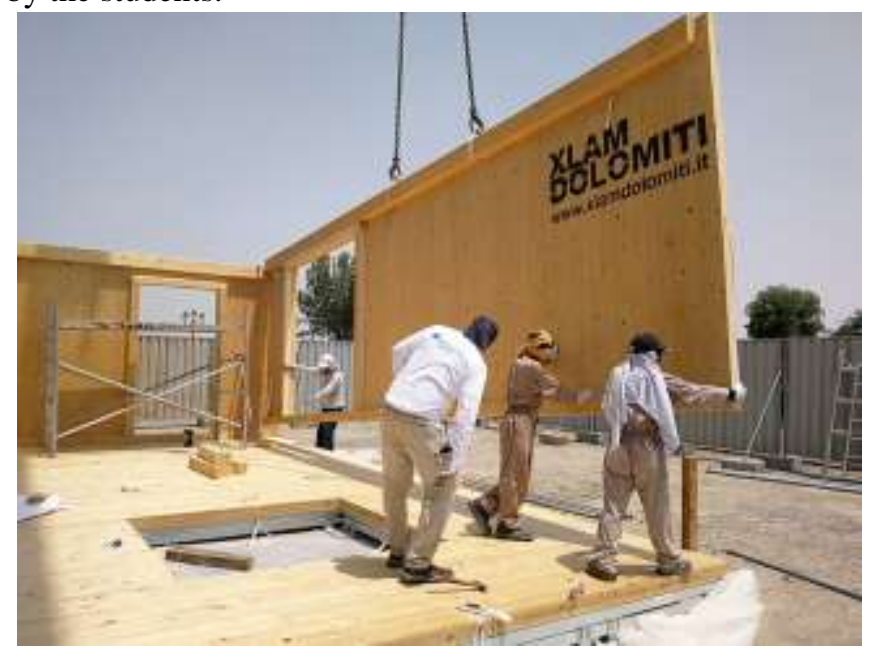

Fig. 4. Students, instructors, and laborers at work during the pre-assembly, at the site on campus at the University of Sharjah.

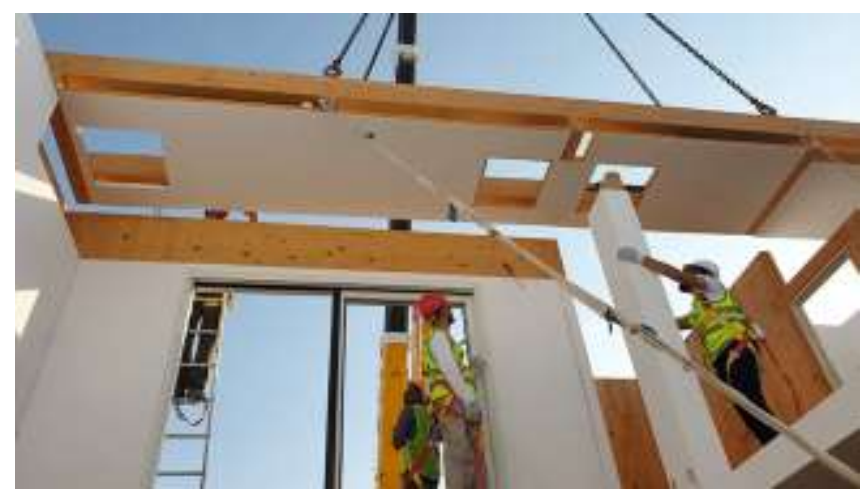

Fig. 5. Students at work during the re-assembly at competition site, supervised by instructors.

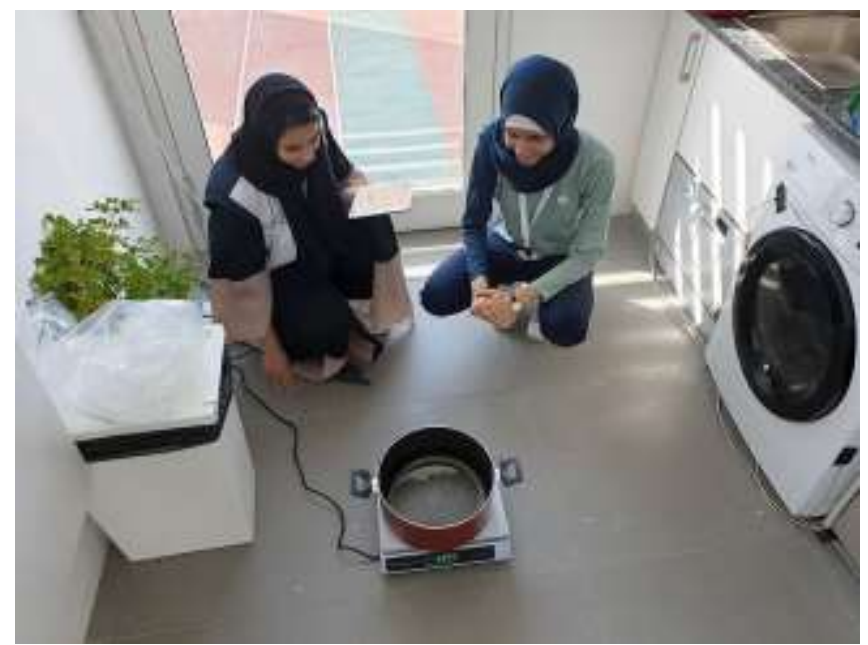

Fig. 6. A student team member performing a house task (kitchen daily cooking consumption), before the evaluation of a competition juror. 


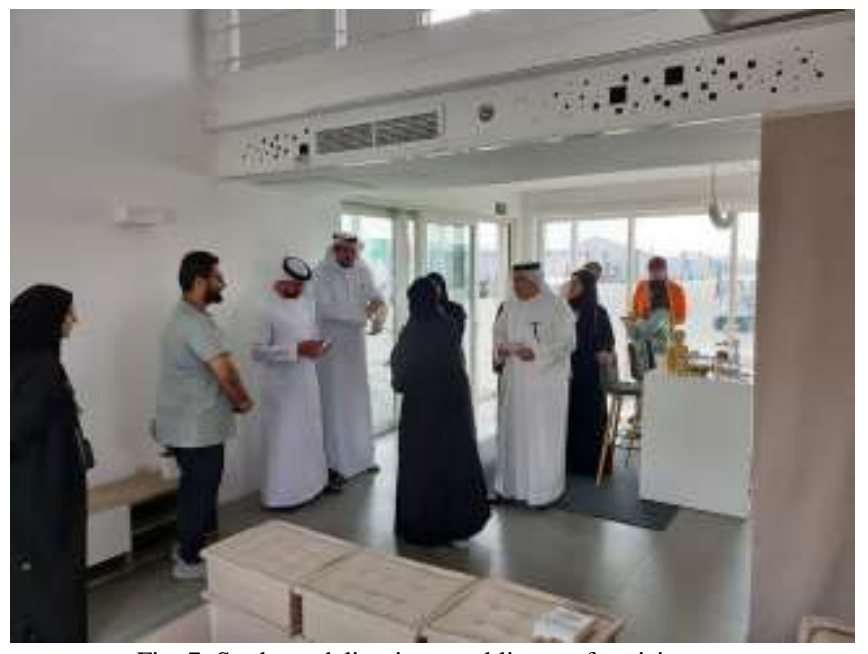

Fig. 7. Students delivering a public tour for visitors.

\section{INTERNATIONAL COOPERATION}

\section{A. Role of the university in the international know-how transfer to the industry}

Universities can have a strategic role for the economic and social progress of local and international industry. As Bozeman et al. (2015) assert, knowledge transfer has been used to add economic and social value and to drive industry development providing services to faculty, enhancing innovation and the practical use of research results, generating additional income streams, fostering local economic development, complying with national and institutional policies [10].

One of the main and final goals of the SDME project is related with the framework of the knowledge transfer. The international collaboration between the University of Sharjah - UAE and the University of Ferrara - Italy allowed testing the participation of industry in academia thanks to different approaches:

- Creation of innovation for strategic improvement of buildings construction sector;

- Involvement of students in this process.

The European (and Italian) background in terms of green buildings and energy efficiency is very structured, restrictive and demanding (Directive 2010/31/UE [11]) and Member States have given start to several strategic plans to improve the building sector. This significant know-how and the related awareness of the sector's actors could help modifying the current trend of research that are focused on the verification of performance levels of products and solutions already successful on the market (Baratta, 2014 [12]), towards experimental research which could produce real entrepreneurial innovation.

The knowledge transfer provided by the University of Ferrara can be described, using the definitions by Giuri et al. [13], "Service-to-faculty strategy" and "Local Development strategy" as it aimed to contribute to the growth of the local economy by generating opportunities for the birth of new companies (or the expatriation of foreign ones) through the application of green building knowledge outside of academia.

\section{B. Students: an added value in the knowledge transfer}

The involvement of students, peculiar pillar of the project, enriches the knowledge transfer objective. The network generated by the international collaboration and the students' work aims at creating opportunities for job mobility and the development of technologies that match the interests and skills of local firms. The idea is creating a link between the word of industry and the educational one providing skilled professionals to a construction sector that is tending toward green-building standards.

To describe this mix of knowledge transfer methods it could be used the expression of Kutvonen et al. (2013) "open innovation" "that has emerged as a new response to manage the increased amount of boundary-spanning knowledge flows in and out of the innovation process» [14]. Students started from the study of the traditional and current market to identify new requirements and possible new boundary of innovation in the context of green building. In particular, they studied, with the support of Italian know-how, the world of timber architecture, and they developed a new construction process to adapt and to export this technology for the colonization of new territory (in an economic and tangible sense). The possibility to improve the efficiency of the system and the adjustment of techniques and materials to the new market were at the base of the project. Students, with improved education and skills, moved as entrepreneurs between academia and business world. The know-how transfer was the result of a merging process of different cultural, social and legislative aspects that characterized the international collaboration.

\section{DISCUSSION AND CONCLUSIONS}

This paper presents a practical approach to educate engineering students to sustainability in the built environment, as the current trend is for this sector to move in this direction.

The UAE fast-growing construction market is constantly influenced by international trends and very quick in receiving and implementing the newest recommendations. Environmental sustainability and energy efficiency will play a relevant role in the future professional life of the next generation of architects and engineers.

Furthermore, the upgrading UAE building market demands for professionals with practical skills and expertise, which can guarantee readiness to take over construction sites and complex project management operation.

Universities have the duty of educating students to the level required by the market. To this regard, the University of Sharjah and the University of Ferrara saw in the SDME 2018 an opportunity to implement practical teaching methods that, 
otherwise, would hardly find space in the core theoretical academic curriculum.

The project directly engaged students in practical activities to simulate a full architectural-engineering design: brainstorming, creative problem solving, networking and cooperating with external institutions, companies, and professional actors enriched the educational experience, and made it successful in creating sustainability-aware young professionals.

Among the many positive results that the project achieved, it thrived to instill in students a feeling of responsibility for the task they were pursuing, which led them to grow fond of it and ultimately to be more committed to its accomplishment. Responsibility can be considered a soft-skill, often directly demanded by employers in interviews, as it characterizes good team-workers and future leaders.

In November 2018 the team finally accomplished the construction of the prototype house (Fig. 8). Starting from June 2016, about 60 students have been involved, during the over 2 years project, in the design phase, construction, and lastly operation and management.

Team KNOW HOWse is one of the 15 teams, out of the initial 22 shortlisted in 2016, to reach the final stage of the competition. The team ranked 8th in the final ranking, and first among the Middle Eastern team-leading universities, for which it received a special award.

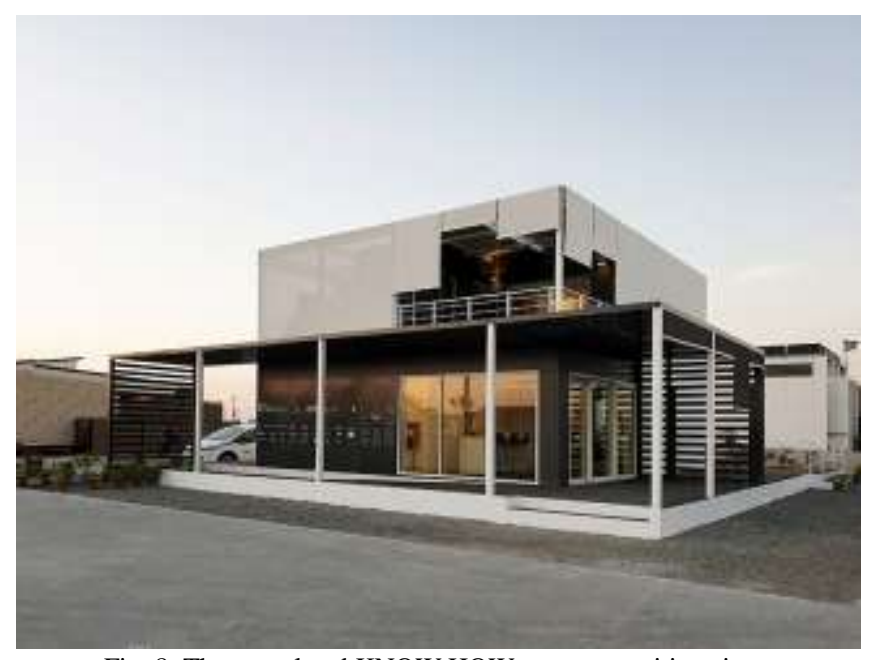

Fig. 8. The completed KNOW HOWse at competition site.

\section{REFERENCES}

[1] UAE Vision 2021, https://www.vision2021.ae/en, last visited January $18,2019$.

[2] International Energy Agency, http://www.iea.org, last visited January $18,2019$.

[3] WWF, The Living Planet Report 2006, https://www.wwf.or.jp/activities/lib/lpr/WWF_LPR_2014.pdf, last visited January 18, 2019.

[4] City Population, http://www.citypopulation.de/UAE.html, last visited January 18, 2019.

[5] L. El Saad “Averting Crisis: Managing Energy Use in Abu Dhabi”, Carboun Journal. Middle East Sustainable Cities, October 2011. Available online at: http://www.carboun.com/energy/averting-crisis-managing-energy-use -in-abu-dhabi//, last visited January 18, 2019.

[6] Solar Decathlon Middle East 2018 - Dubai, http://solardecathlonme.com, last visited January 18, 2019.

[7] DEWA - $\quad$ Dubai Electricity \& 2019

[8] The Know Howse, http://www.knowhowse.ae, last visited January 18, 2019.

[9] Design Builder, https://www.designbuilder.co.uk, last visited January 18, 2019.

[10] B. Bozeman, H. Rimes, J. Youtie, "The evolving state-of-the-art in technology transfer research: revisiting the contingent effectiveness model", Res. Policy 44 (1), 2015, pp. 34-49.

[11] Directive 2010/31/EU of the European Parliament and of the Council of 19 May 2010 on the energy performance of buildings

[12] A. F. L. Baratta, "Technological transfer in an industrial sector in crisis. The relationship between universities and the clay brick and roofing tile industry in Italy", Techne - Journal of technology for Architecture and Environment n. 8, 2014, pp. 54-61.

[13] P. Giuri, F. Munari, A. Scandura and L. Toschi, "The strategic orientation of universities in knowledge transfer activitie", Technological Forecasting \& Social Change 138, 2019, pp. 261-278.

[14] A. Kutvonen, M. Kautonen, J. Tuunainen, J. Lehenkari, I. Savitskaya and R. Muhonen, "Challenges and Solutions for Fostering Entrepreneurial Universities and Collaborative Innovation", Proceedings of the University-Industry Interaction Conference, Amsterdam, May 2013. 